\title{
Novel O-palmitolylated beta-E1 subunit of pyruvate dehydrogenase is phosphorylated during ischemia/reperfusion injury
}

\author{
Clifford DL Folmes ${ }^{\dagger 1}$, Grzegorz Sawicki+2,3, Virgilio JJ Cadete2, Grant Masson¹, Amy J Barr¹ and Gary D Lopaschuk*1
}

\begin{abstract}
Background: During and following myocardial ischemia, glucose oxidation rates are low and fatty acids dominate as a source of oxidative metabolism. This metabolic phenotype is associated with contractile dysfunction during reperfusion. To determine the mechanism of this reliance on fatty acid oxidation as a source of ATP generation, a functional proteomics approach was utilized.

Results: 2-D gel electrophoresis of mitochondria from working rat hearts subjected to 25 minutes of global no flow ischemia followed by 40 minutes of aerobic reperfusion identified 32 changes in protein abundance compared to aerobic controls. Of the five proteins with the greatest change in abundance, two were increased (long chain acylcoenzyme A dehydrogenase (48 \pm 1 versus $39 \pm 3$ arbitrary units, $n=3, P<0.05)$ and a subunit of ATP synthase (189 \pm 15 versus $113 \pm 23$ arbitrary units, $n=3, P<0.05)$ ), while two were decreased ( $24 \mathrm{kDa}$ subunit of NADH-ubiquinone oxidoreductase (94 \pm 7 versus $127 \pm 9$ arbitrary units, $n=3, P<0.05)$ and $D$ subunit of ATP synthase $(230 \pm 11$ versus $368 \pm 47$ arbitrary units, $n=3, P<05)$ ). Two forms of pyruvate dehydrogenase $\beta E 1$ subunit, the rate-limiting enzyme for glucose oxidation, were also identified. The protein level of the more acidic form of pyruvate dehydrogenase was reduced during reperfusion ( $37 \pm 4$ versus $56 \pm 7$ arbitrary units, $n=3, P<05$ ), while the more basic form remained unchanged. The more acidic isoform was found to be O-palmitoylated, while both isoforms exhibited ischemia/ reperfusion-induced phosphorylation. In silico analysis identified the putative kinases as the insulin receptor kinase for the more basic form and protein kinase $C \zeta$ or protein kinase A for the more acidic form. These modifications of pyruvate dehydrogenase are associated with a 35\% decrease in glucose oxidation during reperfusion.

Conclusions: Cardiac ischemia/reperfusion induces significant changes to a number of metabolic proteins of the mitochondrial proteome. In particular, ischemia/reperfusion induced the post-translational modification of pyruvate dehydrogenase, the rate-limiting step of glucose oxidation, which is associated with a $35 \%$ decrease in glucose oxidation during reperfusion. Therefore these post-translational modifications may have important implications in the regulation of myocardial energy metabolism.
\end{abstract}

\section{Background}

Myocardial ischemia results from the transient blockage of the systemic circulation due to a number of mechanisms including atherosclerosis, embolism and surgical procedures resulting in a mismatch between the oxygen requirement of the heart and the oxygen supplied via the coronary circulation. Although many studies have exam-

\footnotetext{
* Correspondence: gary.lopaschuk@ualberta.ca

${ }^{1}$ Cardiovascular Research Group and the Departments of Pharmacology and

Pediatrics, The University of Alberta, Edmonton, Alberta, Canada

+ Contributed equally

Full list of author information is available at the end of the article
}

ined ischemia/reperfusion (I/R) injury and possible therapeutic strategies, the exact molecular and cellular mechanisms continue to be elusive and it remains devastating cause of morbidity and mortality worldwide. Proteomics provides a powerful experimental approach for the observing the global changes in protein abundance and has recently been used to identify novel post-translational modifications (PTMs) of these proteins [1,2]. Utilizing this approach, several studies have examined the I/ $\mathrm{R}$ and preconditioning induced changes of the heart proteome [3-8]. Interestingly, many of the identified proteins have important functions in cardiac energy metabolism, 
which suggests an important role for alterations in metabolism as a contributor to the pathophysiology of I/ R injury.

Under normal aerobic conditions, the heart preferentially metabolizes fatty acids, which contribute between $60 \%$ and $80 \%$ of the required ATP [9]. However, during reperfusion fatty acid oxidation quickly recovers, at the expense of glucose oxidation, and predominates as the main source of mitochondrial oxidative metabolism [1012]. This is believed to be due to the exposure of the heart to high levels of circulating fatty acids, as well as to subcellular changes in the control of myocardial fatty acid oxidation $[13,14]$. In addition, anaerobic glycolysis increases and becomes an important source of ATP for the maintenance of ion gradients in the cardiomyocyte during ischemia [15]. However, if the pyruvate from glycolysis is not subsequently oxidized, and glycolytically derived ATP is hydrolyzed, there is a net production of both lactate and protons due to the uncoupling of glycolysis from glucose oxidation [16,17]. The protons produced are a major contributor to the intracellular acidosis that is associated with ischemia. This acidosis can lead to adverse events, including accelerated sarcolemmal $\mathrm{Na}^{+} /$ $\mathrm{H}^{+}$exchange resulting in intracellular $\mathrm{Na}^{+}$and $\mathrm{Ca}^{2+}$ overload [18], the initiation of cardiac arrhythmias $[19,20]$ and a decreased response of contractile proteins to $\mathrm{Ca}^{2+}$ [19]. If the pyruvate from glycolysis is aerobically metabolized (i.e. glucose oxidation), then lactate and protons are not produced, leading to improved functional recovery during reperfusion [21].

The majority of the heart's essential catabolic machinery resides in the mitochondria. Despite the fact that the human heart mitochondrial proteome has been resolved and approximately $50 \%$ of the identified proteins are involved in metabolism [22], only a few studies has specifically examined the $I / R$ induced global changes in the mitochondrial proteome $[7,8]$. In this study we used a proteomics approach to observe the I/R induced changes in abundance of mitochondrial proteins, one of which was identified as the $\beta E 1$ subunit of pyruvate dehydrogenase $\left(\mathrm{PDH}_{\beta E 1}\right)$, a key regulatory enzyme that directly modulates the rates of glucose oxidation. We subsequently demonstrated that this subunit contains novel post-translational modification (PTMs). These PTMs may lead to the changes in enzyme activity, and are therefore potentially sites regulating myocardial energy metabolism during ischemia and reperfusion.

\section{Methods}

\section{Animals}

The University of Alberta adheres to the principles for biomedical research involving animals developed by the Council for International Organizations of Medical Sci- ences and complies with Canadian Council of Animal Care guidelines.

\section{Isolated working rat hearts}

Rat hearts were cannulated for isolated working heart perfusions as described previously [23]. 9 biological replicates per group were utilized for cardiac function with 6 of these biological replicates utilized for measurement of myocardial metabolism and 3 biological replicates utilized for subsequent 2-D PAGE analysis. In brief, male Sprague-Dawley rats $(0.25-0.3 \mathrm{Kg})$ were anesthetized with sodium pentobarbital (60 mg/Kg i.p.), and the hearts were quickly excised, and the aorta and left atria cannulated. Oxygenated Krebs-Henseleit solution containing $1.2 \mathrm{mM}$ palmitate bound to 3\% BSA, $5 \mathrm{mM}$ glucose, and $100 \mu \mathrm{U} / \mathrm{mL}$ insulin was delivered to the left atrium at a preload pressure of $11.5 \mathrm{mmHg}$. One series of hearts was perfused for $35 \mathrm{~min}$ of aerobic perfusion, $25 \mathrm{~min}$ of global no-flow ischemia, followed by 40 min of aerobic reperfusion. This time of ischemia results in myocardial stunning without significant myocardial necrosis and was chosen to result in approximately $30 \%$ recovery of mechanical function during reperfusion. Another series of hearts underwent $100 \mathrm{~min}$ of aerobic perfusion to serve as a time-matched aerobic control group. These hearts were immediately removed after the perfusion protocol and mitochondria were isolated using a differential centrifugation protocol previously described [24]. Cardiac work was calculated as the product of aortic systolic pressure, measured by a Gould P21 pressure transducer (Harvard Apparatus) connected to the aortic outflow line, and cardiac output, measured with a T206 ultrasonic flow probe (Transonic Systems Inc.) in the preload line.

\section{Measurement of glucose and palmitate oxidation}

An additional series of hearts were perfused using the I/R protocol to measure rates of myocardial energy metabolism. Glucose oxidation and palmitate oxidation were measured by perfusing hearts with $\left[\mathrm{U}-{ }^{14} \mathrm{C}\right]$ glucose or $\left[9,10-{ }^{3} \mathrm{H}\right]$ palmitate, respectively, with quantitative measurement of ${ }^{14} \mathrm{CO}_{2}$ or ${ }^{3} \mathrm{H}_{2} \mathrm{O}$ production, as described previously [23].

\section{Isolation of Mitochondria}

After the perfusions, the hearts were quickly rinsed in ice-cold $225 \mathrm{mM}$ mannitol, $75 \mathrm{mM}$ sucrose, $1 \mathrm{mM}$ EGTA, $10 \mathrm{mM}$ Tris, pH 7.5 (MSE buffer). The atria were removed and the ventricles minced. A 20\% (w/v) tissue suspension in MSE buffer was adjusted between $\mathrm{pH} 7.4$ to 7.5. The suspension was homogenized with a Polytron homogenizer for two 10 -second periods. The homogenate was centrifuged at $480 \times \mathrm{g}$ for $5 \mathrm{~min}$, and the supernatant (S1) was filtered through cheese cloth and centrifuged at $10,000 \times \mathrm{g}$ for $30 \mathrm{~min}$. The pellet $(\mathrm{Pi})$, from 
the $480 \times \mathrm{g}$ spin, was suspended in MSE buffer and homogenized again under the same settings and centrifuged at $480 \times \mathrm{g}$ for $5 \mathrm{~min}$. The supernatant (S2) was filtered through cheesecloth and was centrifuged at 10,000 $\times \mathrm{g}$ for $30 \mathrm{~min}$. The $\mathrm{S} 2$ pellet was combined with the S1 pellet suspended using MSE buffer and centrifuged at $10,000 \times \mathrm{g}$ for $30 \mathrm{~min}$. The resulting pelleted mitochondria (S3) was suspended in a urea solution in a 1:2 (w/v) ratio and used for 2D electrophoresis [24]. Mitochondrial purity was assessed by Western blotting for the cytosolic marker, GAPDH (Abcam) and mitochondrial marker, mitochondrial creatine kinase (mtCK, Abcam).

\section{Preparation of mitochondria extracts}

Protein samples for 2-D electrophoresis were prepared at room temperature by mixing one part of the mitochondria pellet with two parts (w:v) of rehydration buffer $(8$ $\mathrm{mol} / \mathrm{L}$ urea, 4\% CHAPS, $10 \mathrm{mmol} / \mathrm{L}$ DTT, 0.2\% Bio-Lytes $3 / 10$ [BioRad]). Samples were sonicated twice for $5 \mathrm{~s}$ and centrifuged for $10 \mathrm{~min}$ at 10,000 $\mathrm{g}$ at room temperature to remove any insoluble particles. Protein content of the mitochondrial extract in rehydration buffer was measured using the BioRad protein assay.

\section{Two-dimensional polyacrylamide gel electrophoresis}

$400 \mu \mathrm{g}$ of mitochondria extract protein was originally applied to $11 \mathrm{~cm}$ immobilized $\mathrm{pH}$ gradient strip with linear $\mathrm{pH}$ gradient from 3 to 10 (IPG, Biorad) and equilibrated for $16-18 \mathrm{hr}$ at $20^{\circ} \mathrm{C}$ in rehydration buffer, however we subsequent utilized a $\mathrm{pH}$ gradient of 5 to 8 to increase the resolution and separation of protein spots. These conditions have been previously validated to result in even protein loading [25]. For isoelectrofocusing, the BioRad Protean isoelectrofocusing cell was used with the conditions described previously [26]. The second dimension of electrophoresis was carried out using 8-16\% acrylamide Criterion precast gradient gels (BioRad). To minimize variations in resolving proteins during the second dimension run, all gels were run simultaneously using a Criterion Dodeca Cell (BioRad). After separation, proteins were detected using Coomassie Brilliant Blue R250 (BioRad). Developed gels were scanned using a calibrated GS-800 densitometer (BioRad). Quantitative analysis of spot intensity from 2-D electrophoresis was measured using PDQuest 7.1 software (BioRad). Only protein spots with a relative intensity between 10-100 arbitrary units were considered for analysis. Using these criteria for protein resolution and staining, we were able to obtain high reproducibility to analyze both a single protein from the same sample run in different gels and for a specific protein spot from different heart samples. 3 analytical replicates were utilized for 2-D PAGE and subsequent mass spectrometry identification.

\section{Mass spectrometry}

Protein spots were manually excised from the 2-D gel. Subsequently, in-gel trypic digests were analyzed using a Bruker Ultraflex TOF/TOF mass spectrometer. Digests were applied to an AnchorChip plate (Bruker) as previously described [27]. Mass spectra and tandem mass spectra were then obtained in an automated fashion using the AutoXecute function. Typically 100 shots were accumulated to generate a peptide mass fingerprint. The 5 most intense peaks were then selected to have MS/MS performed where 400 shots on average were used to generate a MS/MS profile (3 analytical replicates). Peaklist generation and peak picking was performed using Flexanalysis 2.2 SNAP (sophisticated numerical annotation procedure), with default setting for peaklist generation. For PMF data the $\mathrm{S} / \mathrm{N}$ threshold $=6$, resolution $>6000$, they were externally calibrated using 8 peptides with $\mathrm{m} / \mathrm{z}$ ranging from 757.39 to 3147.47 and tryptic autolytic peptides are excluded. Acceptance criteria for MS/MS was at least 2 matching peptides with a score $\mathrm{P}<05$. The resultant MS or MS/MS data was searched using the MASCOT version 2.2 http://www.matrixscience.com search engine against NCBInr (2007) and Swiss-Prot (2007) databases. Specified 68,229 protein sequences from NCBInr for Rattus Norvegicus was used for identification of the proteins. The Mowse scoring algorithm was used for justification of protein identification [28].

\section{Calculation of the theoretical masses of $\mathrm{PDH} \beta$ peptides generated by the enzymatic cleavage}

PeptideMass $\quad \underline{\text { http://au.expasy.org/tools/peptide- }}$ mass.html was used to predict the mass of trypsindigested peptides from the sequence of $\mathrm{PDH} \beta$. For calculation of theoretical peptide masses we assumed: 1) incomplete protein digestion (1 missed cleavage level) and $\pm 0.2 \mathrm{Da}$ error windows on experimental peptide mass values and for MS/MS fragment ion mass values, 2) mandatory alkylation and reduction of cysteines with iodoacteamide, and 3) variable oxidation of methionine. Only peptides bigger than 500 Da were considered.

\section{Examination of experimental peptide mass fingerprinting for post-translational modifications (PTMs)}

FindMod tool (2007) was used to find potential PTMs http://au.expasy.org/tools/findmod/ in the experimental peptides of PDH $\beta$. 22 types of PTMs were considered with the assumption that up to 3 PTM in one peptide can exists.

\section{Chemical verification of $\mathrm{O}$-palmitolyation}

Experimental peptides with identified (in silico) palmitoylation were incubated with $0.1 \mathrm{M} \mathrm{KOH}$ for $4 \mathrm{hr}$ at room temperature [29] and analysed by MALDI TOFTOF. 
Verification of phosphorylation by dephosphorylation of peptide with alkaline phosphatase

Experimental peptides with identified (In silico) phosphorylation were incubated with 0.5 unit of alkaline phospatase in $50 \mathrm{mM}$ bicarbonate solution for $120 \mathrm{~min}$ at $30^{\circ} \mathrm{C}$ and analyzed by MALDI TOF-TOF [30].

\section{Prediction of kinases that phosphorylate the $\beta E 1$ PDH}

PDH phosphorylating kinases were predicted using phosphorylation consensus sequences identified with Scansite http://scansite.mit.edu/ and NetPhosK 1.0 Sever http:// www.cbs.dtu.dk/services/NetPhosK/.

\section{Western blotting}

Protein $(30 \mu \mathrm{g})$ from heart homogenate or from mitochondria preparation was separated using $12 \%$ SDSPAGE and transferred to a PVDF membrane (Bio-Rad). Glyceraldehydes 3-phosphate dehydrogenase (GAPDH) was identified using mouse monoclonal anti-GAPDH antibody (Abcam). Mitochondrial creatine kinase (mtCK) was identified with rabbit polyclonal anti-mtCK antibody (Abcam). Band densities were measured using Versa Doc 5000 and Quantity One 4.6 software (Bio-Rad).

\section{Statistical analysis}

Data are shown as mean \pm SEM. Analysis of functional data, the protein spots in the 2-D electrophoresis experiments and metabolic data were performed using unpaired $\mathrm{t}$-tests. A value of $\mathrm{p}<0.05$ was considered statistically significant.

\section{Results}

\section{Cardiac function in hearts subjected to aerobic perfusion} and $\mathrm{I} / \mathrm{R}$

Hearts were perfused either for $100 \mathrm{~min}$ aerobically, or for $35 \mathrm{~min}$ aerobically followed by $25 \mathrm{~min}$ of global ischemia and $40 \mathrm{~min}$ of reperfusion (Figure 1A). The functional recovery of hearts subjected to $I / R$ was significantly reduced compared to hearts aerobically perfused for $100 \mathrm{~min}$ (Figure 1B). Glucose oxidation rates were decreased by $35 \%$ in reperfused hearts compared to the average glucose oxidation rates in time-matched aerobic control hearts (Figure 1C). Despite this reduction in glucose oxidation rates, palmitate oxidation rates did not differ between the $I / R$ group and the aerobic controls (Figure 1D).

\section{2-D Electrophoresis and identification of proteins}

The mitochondrial isolation resulted in a similar yield of mitochondria ( $97 \pm 8$ and $102 \pm 8 \mathrm{mg}$ mitochondria/g wet heart weight) with enriched expression of $\mathrm{mtCK}$ and free of contamination by cytosolic GAPDH (Figure 2A). 2-D PAGE identified $32 \mathrm{I} / \mathrm{R}$-induced changes in protein levels out of approximately 260 protein spots observed in all of the gels and we chose to identify the five spots with the

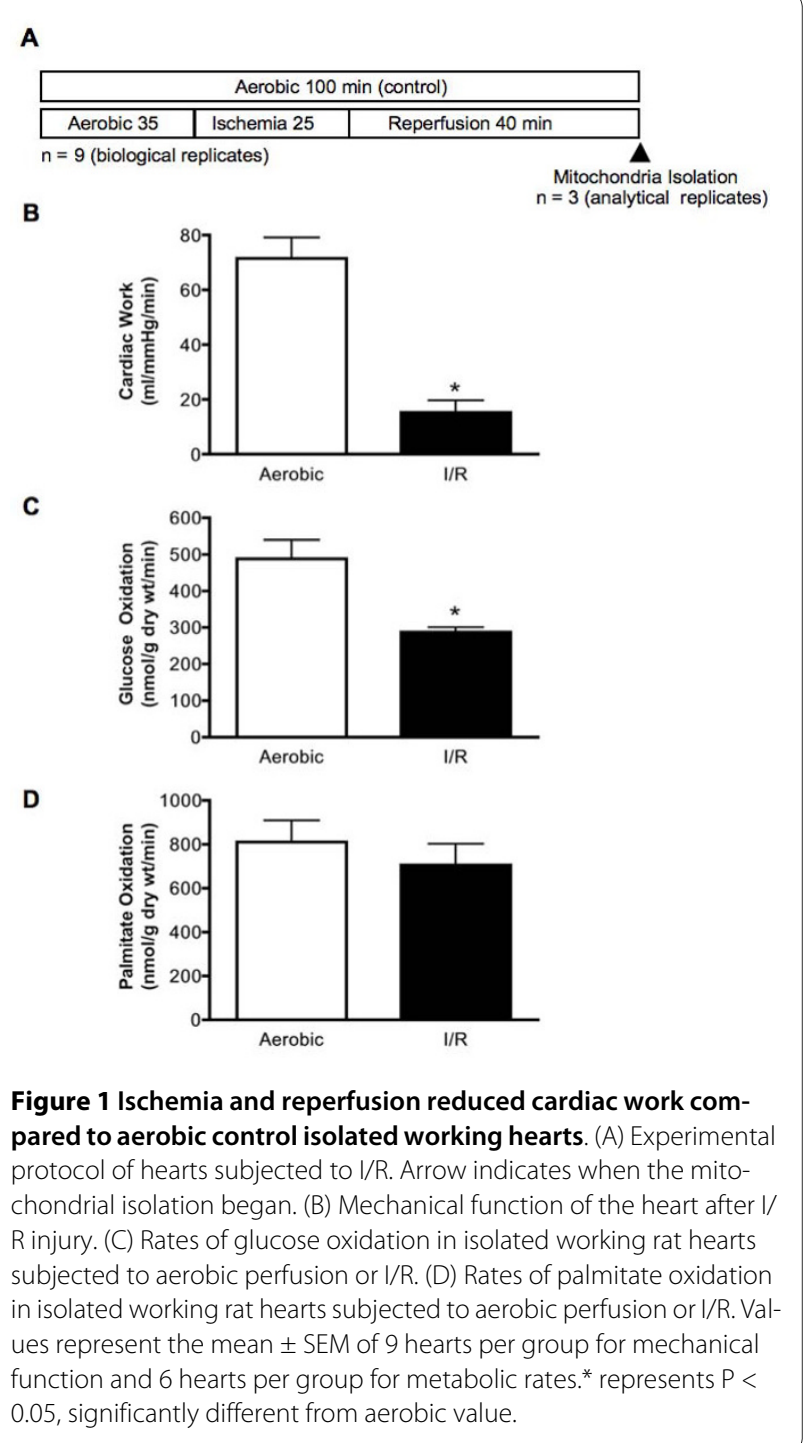

greatest change in abundance (Figure 2B, $\mathrm{C}$ and Table 1). Mass spectrometry analysis of all five protein spots gave only one protein hit above the threshold for each search. The high Moswe scores show high level of accuracy for each identification (Table 1). Two of these protein abundances were increased with $I / R$ and were identified as long chain acyl-coenzyme A dehydrogenase and ATP synthase ( $\alpha$ subunit). Three of these protein abundances were decreased with I/R and were identified as NADHubiquinone oxidoreductase ( $24 \mathrm{kDa}$ subunit), ATP synthase (D subunit) and PDH ( $\beta E 1$ subunit). In addition, the protein spot adjacent to spot 2 was also identified as $\mathrm{PDH}_{\beta E 1}$ (Table 2). For the remainder of this study we concentrated on post-translational changes induced in PDH due to the importance of this enzyme in the regulation of myocardial glucose oxidation. Both aerobic and $I / R$ groups expressed two molecular forms of $\mathrm{PDH}_{\beta E 1}$ (which we identified as a more acidic form and more basic form 


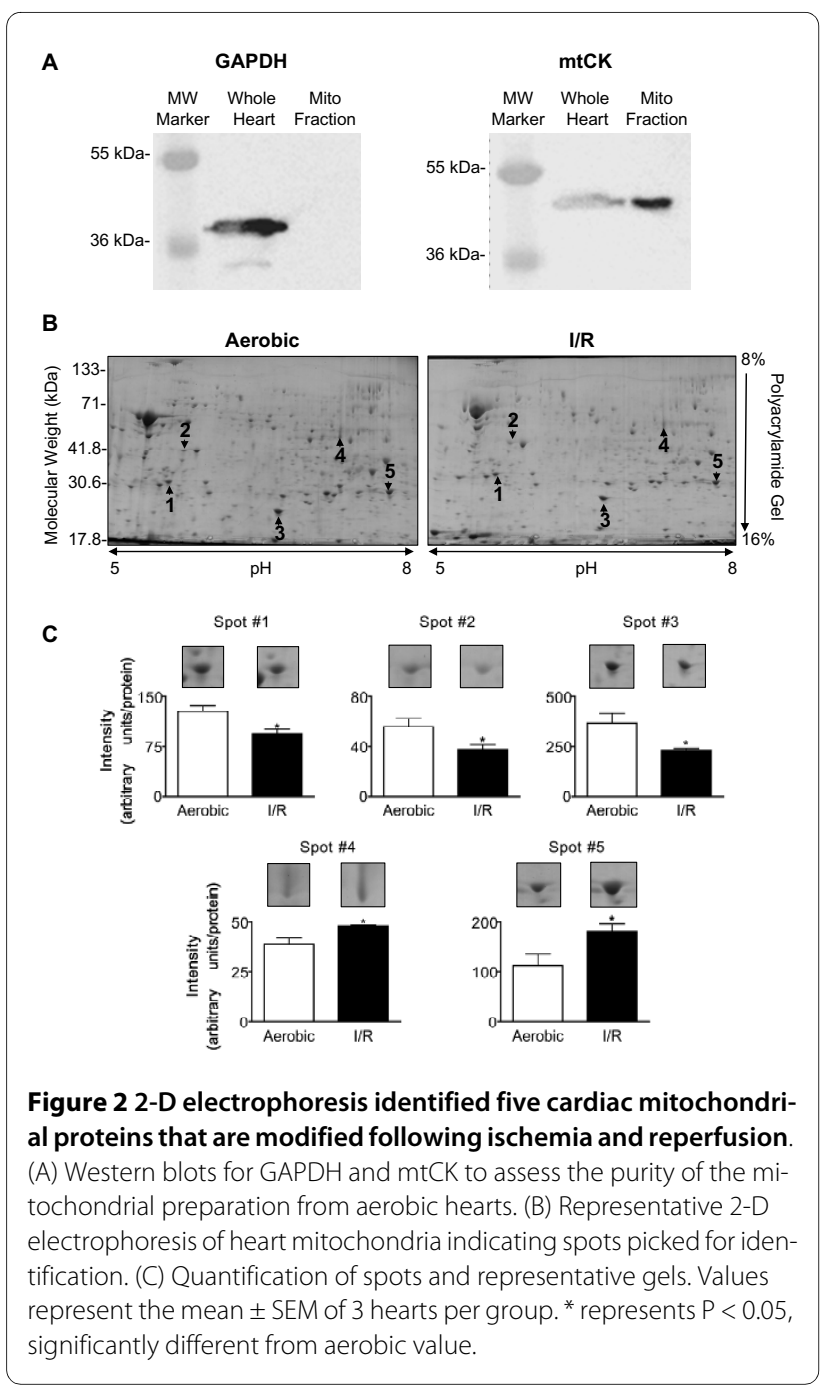

based on their isoelectric point) but only the protein level of the more acidic form was decreased in I/R (Figure 3B).

Protein mass fingerprints (PMFs) and modifications of PDH Proteins were excised from the gels and subjected to trypsin digestion followed by mass spectrometry analysis to produce PMFs of both the more acidic and more basic form of the $\beta E 1$ subunit of PDH (Figure 4A). Comparison of trypsin digested peptides of $\mathrm{PDH}_{\beta E 1}$ from control hearts using the FindMod tool showed that the more acidic form is O-palmitoylated (peptide $1493.486 \mathrm{Da}$, Figure $4 \mathrm{~A}$ and $4 \mathrm{~B}$ ). This unique PTM was confirmed by $\mathrm{KOH}$ treatment of the peptides (Figure 4A), which led to the disappearance of the O-palmitoylated peptide and the appearance of a new peptide (1240.931 Da).

Upon comparison of the PMFs from the more acidic form of $\mathrm{PDH}_{\beta E 1}$ from the aerobic and $\mathrm{I} / \mathrm{R}$ hearts, two new peptides with masses $984.579 \mathrm{Da}$ and 2397.998 Da were detected as being putative phosphorylated peptides (Figure 5). However upon treatment with alkaline phos- phatase, only the smaller peptide was removed (Figure 5). Comparison of the PMFs of the more basic form of $\mathrm{PDH}_{\beta E 1}$ from the aerobic and I/R hearts with the Find Mod tool, detected that I/R triggers phosphorylation of the more basic form (peptide 1922.068, Figure 6A and 6B). This peptide peak disappeared after treatment with alkaline phosphatase (Figure 6A). In addition, the isoelectric point of the more basic form of $\mathrm{PDH}_{\beta E 1}$ was decreased in $\mathrm{I} / \mathrm{R}$ hearts (Figure $7 \mathrm{~B}$ ), further supporting the theory that this peptide was phosphorylated.

\section{Identification of putative phosphorylation sites and kinases}

Phosphorylation sites were determined by examining the sizes of trypsin digested protein fragments with the FindMod tool, the kinases were determined using Scansite and the NetPhosK 1.0 Sever. Using this analysis we identified Ser-16 of the more acidic $\mathrm{PDH}_{\beta E 1}$ to be a possible site of phosphorylation with the putative kinase being protein kinase $\mathrm{C} \zeta$ (PKC $\zeta$ ) or protein kinase A (PKA) (Table 3). For the more basic $\mathrm{PDH}_{\beta E 1}$ we identified Tyr-132 as a possible site of phosphorylation with the putative kinase being the insulin receptor kinase (Table 3).

\section{Discussion}

Although there are several reports describing the mitochondrial proteome, only two previous studies have attempted to provide a picture of more global changes in protein abundance induced by $I / R[7,8]$. Using a functional proteomics approach we identified 32 protein spots, which are either up or down regulated by I/R. We focused on the proteins with the largest changes in abundance, which all corresponded to proteins with metabolic functions. The proteins with an increase in abundance included long chain acyl-coenzyme A dehydrogenase and ATP synthase ( $\alpha$ subunit), while proteins with a decrease in abundance included NADH-ubiquinone oxidoreductase (24 kDa subunit), ATP synthase (D subunit) and $\mathrm{PDH}_{\beta E 1}$. Due to the identification of two protein spots corresponding to $\mathrm{PDH}_{\beta E}$ and the critical role $\mathrm{PDH}$ plays in the regulation of myocardial glucose oxidation, we endeavored to better characterize the two molecular forms of $\mathrm{PDH}_{\beta E 1}$. The major difference between the two forms of $\mathrm{PDH}_{\beta E 1}$ is a novel O-palmitoylation PTM to the more acidic form of $\mathrm{PDH}_{\beta E 1}$. In addition, I/R triggered phosphorylation of both forms of $\mathrm{PDH}_{\beta E 1}$ with in silico methods identifying insulin receptor kinase and $\mathrm{PKC}_{\zeta}$ or PKA as the putative kinases the more basic form and acid form respectively.

The mitochondrial PDH complex catalyzes the decarboxylation of pyruvate to acetyl-CoA, and consists of multiple copies of three enzymes (E1 (pyruvate dehydrogenase), E2 (dihydrolipoyl transacetylase) and E3 (dihy- 
Table 1: Mass Spectrometry identification of protein spots using the Mascot Search Engine.

\begin{tabular}{|c|c|c|c|c|c|c|}
\hline \multirow{2}{*}{$\begin{array}{l}\text { Protein } \\
\text { Spot (\#) }\end{array}$} & \multicolumn{2}{|c|}{$\begin{array}{c}\text { Probability Based Mowse } \\
\text { Score* }\end{array}$} & \multicolumn{2}{|c|}{ Peptides } & \multirow{2}{*}{$\begin{array}{c}\text { Sequence } \\
\text { Coverage } \\
\text { (\%) }\end{array}$} & \multirow[t]{2}{*}{ Identification and $\mathrm{AC}^{* *}(\#)$} \\
\hline & $\begin{array}{l}\text { Threshold } \\
(P<0.05)\end{array}$ & $\begin{array}{l}\text { Observed } \\
\text { Score }\end{array}$ & $\begin{array}{l}\text { Matched } \\
\text { (n) }\end{array}$ & $\begin{array}{c}\text { Not matched } \\
\text { (n) }\end{array}$ & & \\
\hline & & & & & & $\mathrm{NADH}$-ubiquinone \\
\hline \multirow[t]{3}{*}{1} & 58 & 141 & 17 & 41 & 44 & oxidoreductase (24 kDa subunit), \\
\hline & & & & & & P19234 \\
\hline & & & & & & Pyruvate dehydrogenase \\
\hline \multirow[t]{3}{*}{2} & 32 & 108 & 3 & 31 & 10 & ( $\beta$ E1 subunit) \\
\hline & & & & & & P49432 \\
\hline & & & & & & ATP synthase \\
\hline \multirow[t]{2}{*}{3} & 58 & 127 & 13 & 40 & 34 & (D subunit) \\
\hline & & & & & & P31399 \\
\hline \multirow[t]{3}{*}{4} & 58 & 127 & 13 & 18 & 34 & Long-chain acyl-CoA dehydrogenase \\
\hline & & & & & & P15650 \\
\hline & & & & & & ATP synthase \\
\hline \multirow[t]{2}{*}{5} & 58 & 87 & 12 & 28 & 41 & (a subunit) \\
\hline & & & & & & P15999 \\
\hline
\end{tabular}

* $-10 \log (P)$ where $P$ is the probability that the observed match is a random event.

**UniProtKB/Swiss-Prot primary accession number

drolipoyl dehydrogenase), with the E1 being a tetramer consisting of $2 \alpha$ and $2 \beta$ subunits. This complex is regulated at multiple levels including allosterically by the substrates and products of the reaction [31] and due to phosphorylation/dephosphorylation of the $\alpha$ chains by the PDK and PDP [32]. Although extensive work has been performed correlating phosphorylation of PDH by the PDKs with activity and pyruvate flux [32], to our knowledge no one has previously reported phosphorylation of $\mathrm{PDH}_{\beta E 1}$. The present study identified novel phosphorylation events on $\mathrm{PDH}_{\beta E 1}$ that may account for the $35 \%$ decrease in glucose oxidation during reperfusion, and sustain inactivation of PDH $[33,34]$. However it is not known what direct effect these phosphorylation events have on the PDH complex and its activity. In silico methods identified $\mathrm{PKC}_{\zeta}$ or PKA as putative kinases responsible for phosphorylating the more acidic form and insulin receptor kinase was identified for the more basic form. Although little evidence connects $\mathrm{PKC}_{\zeta}$ with the regulation of cardiac energy metabolism, several reports have established a role for $\mathrm{PKC}_{\delta}$ [34-36], with the loss of $\mathrm{PKC}_{\delta}$ expression resulting in an increase in the ratio of lipid to

Table 2: Mass Spectrometry identification of protein spots corresponding to the E1 subunit of PDH.

\begin{tabular}{|c|c|c|c|c|c|c|}
\hline \multirow{2}{*}{$\begin{array}{l}\text { Protein } \\
\text { Spot (\#) }\end{array}$} & \multicolumn{2}{|c|}{ Probability Based Mowse Score* } & \multicolumn{2}{|c|}{ Peptides } & \multirow{2}{*}{$\begin{array}{c}\text { Sequence } \\
\text { Coverage } \\
(\%)\end{array}$} & \multirow[t]{2}{*}{ Identification } \\
\hline & $\begin{array}{l}\text { Threshold } \\
(P<0.05)\end{array}$ & $\begin{array}{c}\text { Observed } \\
\text { Score }\end{array}$ & $\begin{array}{c}\text { Matched } \\
\text { (n) }\end{array}$ & Not matched & & \\
\hline 1 Aerobic & 32 & 108 & 3 & 31 & 10 & $\begin{array}{c}\text { Pyruvate dehydrogenase } \\
\text { ( } \beta E 1 \text { subunit) }\end{array}$ \\
\hline 2 Aerobic & 69 & 167 & 21 & 5 & 59 & $\begin{array}{c}\text { Pyruvate dehydrogenase } \\
\text { ( } \beta E 1 \text { subunit) }\end{array}$ \\
\hline $1 \mathrm{I} / \mathrm{R}$ & 31 & 85 & 2 & 40 & 13 & $\begin{array}{c}\text { Pyruvate dehydrogenase } \\
\text { ( } \beta E 1 \text { subunit) }\end{array}$ \\
\hline $2 \mathrm{I} / \mathrm{R}$ & 69 & 151 & 21 & 13 & 59 & $\begin{array}{c}\text { Pyruvate dehydrogenase } \\
\text { ( } \beta E 1 \text { subunit) }\end{array}$ \\
\hline
\end{tabular}

* $-10 \log (P)$ where $P$ is the probability that the observed match is a random event. 


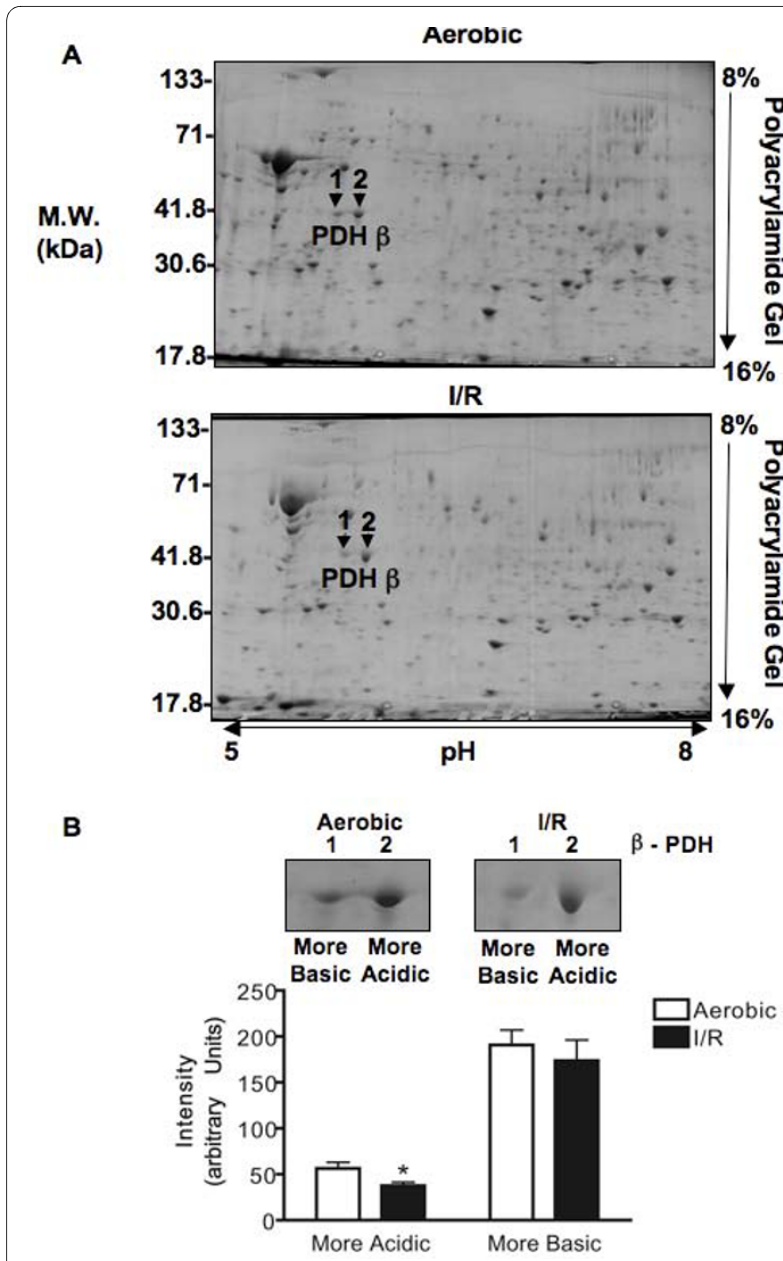

Figure 3 2-D electrophoresis identified two forms of the $\beta E 1$ of pyruvate dehydrogenase (PDH). (A) Representative 2-D electrophoresis of heart mitochondria indicating spots identified as $\beta E 1$ subunit of PDH. (B) Quantification of spots identified as the $\beta E 1$ of PDH peptides and representative gels. Values represent the mean \pm SEM of 3 hearts per group. * represents $P<0.05$, significantly different from aerobic value.

glucose metabolites and impaired cardioprotection due to ischemic preconditioning [35,37]. Translocation of $\mathrm{PKC}_{\delta}$ to the mitochondria results in differential expression of the PDH complex and the direct binding of $\mathrm{PKC}_{\delta}$ to PDK2 can promotes phosphorylation-dependent inhibition of PDH $[34,36]$. The present study would suggest that $\mathrm{PKC}$ might also directly phosphorylate $\mathrm{PDH}_{\mathrm{E} 1 \beta}$ to exert its effects on $\mathrm{PDH}$ activity. An alternative hypothesis would be that phosphorylation at this site by PKA stimulates PDH activity, as previous reports suggest that treatment of isolated hearts with cAMP analogues or epinephrine (which signals via cAMP) preferentially increase glucose oxidation via an activation of PDH $[38,39]$. The phosphorylation-induced activation of PDH by insulin receptor kinase would also be consistent with the activation of glucose oxidation by insulin [40].

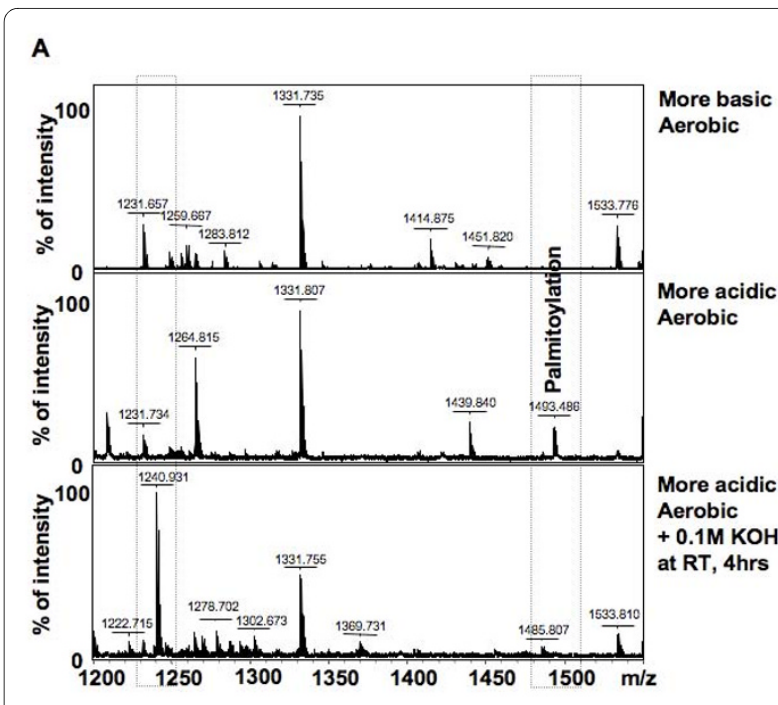

B

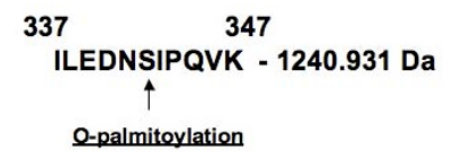

Figure 4 Protein mass fingerprints from aerobic heart mitochondria showing the novel O-palmitoylation of the more acidic form of PDH. (A) PMFs of the more basic and more acidic forms of the $\beta E 1$ of $\mathrm{PDH}$, and the PMF of the more acidic form of the $\beta E 1$ after potassium hydroxide treatment $(0.1 \mathrm{M} \mathrm{KOH}$ room temperature for 4 hours). (B) Potential site of O-palmitoylation of the more acidic form of $\beta E 1$.

Athough there is little evidence implicating insulin in directly regulating PDH activity, there is some suggestion that insulin may activate PDH phosphatase 2, leading to a dephosphoryation and activation of PDH [41]. Five hours of in vivo insulin infusion is sufficient to decrease mRNA of PDK4, however it is unknown if this occurs with acute insulin administration [42]. The identification of these novel phosphorylation sites on $\mathrm{PDH}_{\beta \mathrm{E} 1}$ may have very important implications on the regulation of PDH activity; therefore further studies are required to determine the ability of the putative kinases to phosphorylate these sites in vitro and in vivo and their subsequent effect on PDH activity.

The in silico analysis also identified a novel O-palmitoylation PTM of the more acidic form of $\mathrm{PDH}_{\beta E 1}$, which was confirmed biochemically. To our knowledge this is the first report of this modification in a mitochondrial protein. This finding may be of functional significance, as only protein levels of the O-palmitoylated form of $\mathrm{PDH}_{\beta E 1}$ are decreased during I/R in the heart. Very few studies have reported the existence of O-acylated peptides, with one reporting that the removal of O-palmitoylation from a threonine residue in the insect toxin PLTXII results in significant reduction in biological activity and 


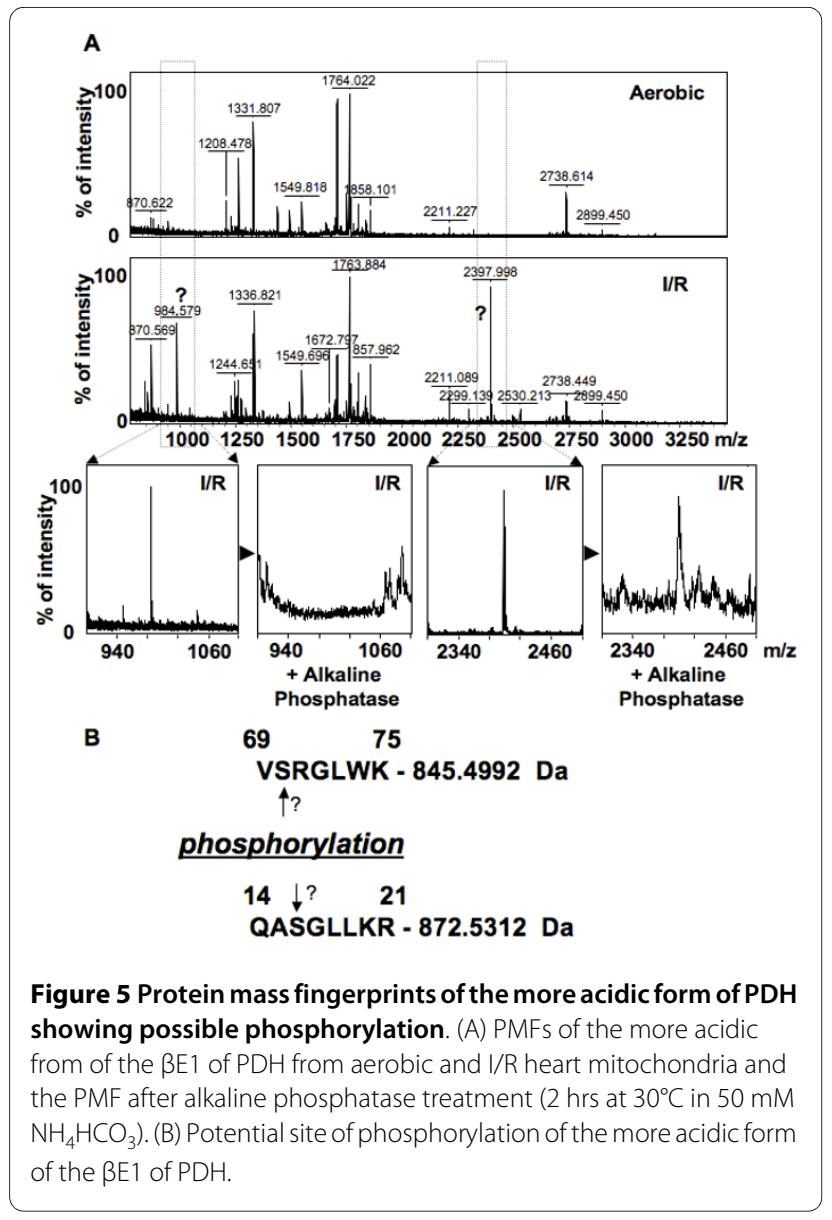

more recently an O-octanylation of a serine residue in ghrelin was identified to be essential for its biological activity $[43,44]$. Due to the scarcity of O-acylation of peptides, no work has been performed on its biological role, however much is known about the S- and N-palmitoylation of proteins [45]. These PTMs tend to promote both membrane association of soluble proteins and targeting of proteins to lipid rafts. As PDH is reported to be localized to the inner mitochondrial membrane in cardiac tissue [46], we hypothesize that palmitoylation of PDH results in its recruitment to the inner mitochondrial membrane, whereby it could interact with the monocarboxylate transport (the transporter required for pyruvate entry into the mitochondria). In this case a reduction in the palmitoylated form of PDH during I/R would result in reduced inner mitochondrial membrane localization of $\mathrm{PDH}$, potentially reducing pyruvate flux and glucose oxidation in the reperfused heart. Further studies are required to assess the effects of palmitoylation on PDH activity, in order to determine its effects on glucose oxidation in the ischemic heart.

A potential limitation of the present study is that our global I/R protocol is mainly a model of myocardial stun-

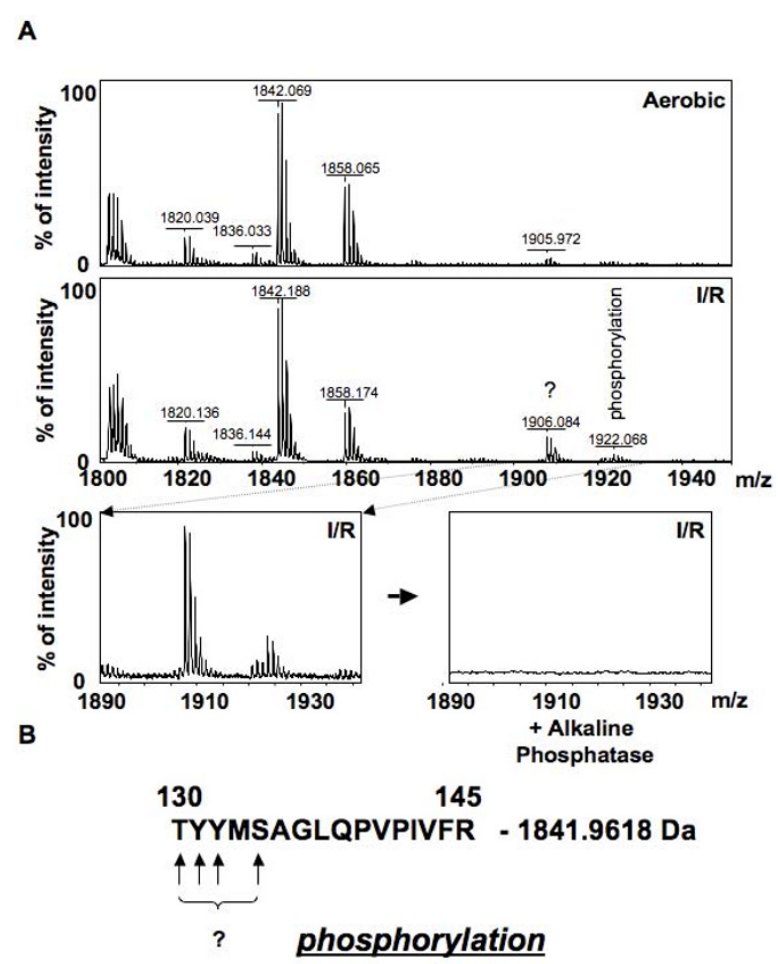

Figure 6 Protein mass fingerprints of the more basic form of PDH showing possible phosphorylation. (A) PMFs of the more basic from of the $\beta E 1$ of PDH from aerobic and I/R heart mitochondria and the PMF after alkaline phosphatase treatment $\left(2 \mathrm{hr}\right.$ at $30^{\circ} \mathrm{C}$ in $50 \mathrm{mM}$ $\mathrm{NH}_{4} \mathrm{HCO}_{3}$ ). (B) Potential site of phosphorylation of the more basic form of the $\beta E 1$ of $P D H$.

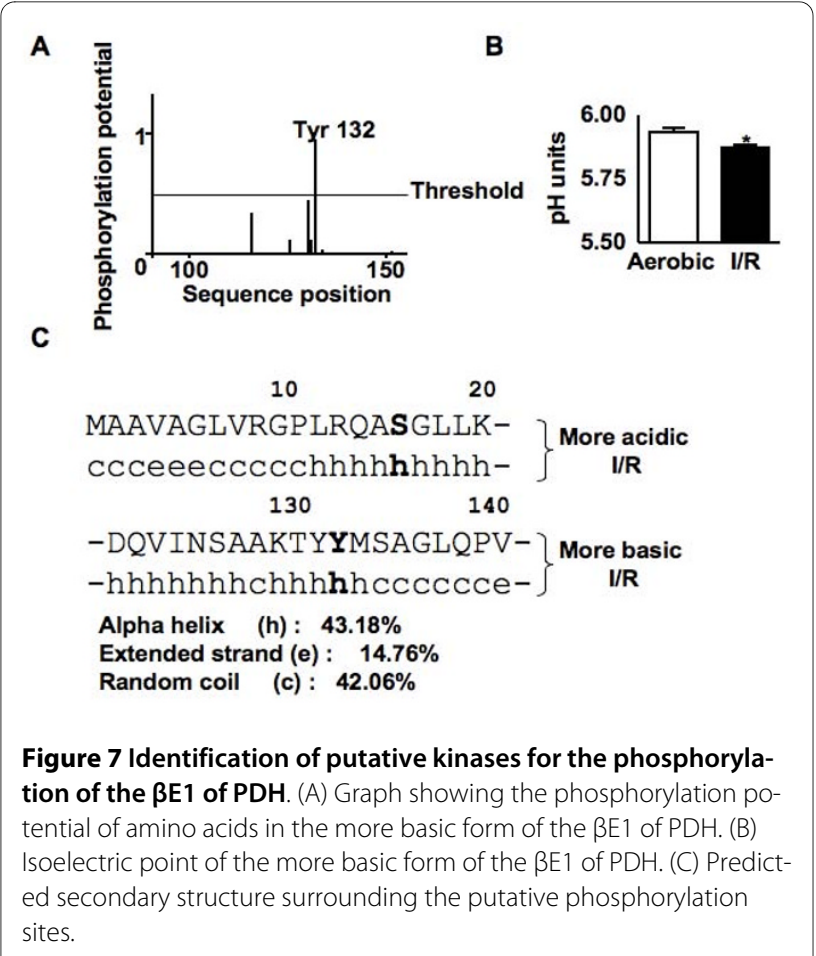


Table 3: Identification of phosphorylation sites and putative kinases for the E1 subunit of PDH.

\begin{tabular}{|c|c|c|c|c|c|}
\hline \multirow[t]{2}{*}{ Isoform Of PDH } & \multirow[t]{2}{*}{ Amino Acid } & \multicolumn{2}{|c|}{ Scansite } & \multicolumn{2}{|c|}{ NetPhosK 1.0 Server } \\
\hline & & Kinase & Score* & Kinase & Score* \\
\hline More Acidic & S16 & PKC & 0.61 & PKA & 0.57 \\
\hline More Acidic & S70 & & & PKA & 0.53 \\
\hline More Basic & $\mathrm{T} 130$ & PKC & & & \\
\hline More Basic & Y131 & & & & \\
\hline More Basic & Y132 & INSR & 0.72 & INSR & 0.55 \\
\hline More Basic & S134 & & & & \\
\hline
\end{tabular}

* Threshold 0.5 (range 0-1)

ning without significant necrosis and apoptosis, which has limited clinical applicability. In addition, only subsarcolemmal mitochondria were isolated using our protocol, as nagarse was not included in our isolation buffer. This protease was omitted because it has been demonstrated that it affects the activity of $\mathrm{NAD}^{+}$glycohydrolase and the rate of NADH hydrolysis, which could potentially modify other metabolic function $[47,48]$. To our knowledge no one has examined the difference in the proteome of subsarcolemmal and interfibrillar mitochondria, therefore it is unknown how this would affect the interpretation of the current data. Although we identified a number of changes in mitochondrial protein abundance, the mechanism by which $\mathrm{I} / \mathrm{R}$ induces these changes is unknown, but may include the release of mitochondrial proteins $[8,49]$, 2) turnover of these proteins (balance between gene expression/protein synthesis and protein degradation) [50-52] and 3) post-translational modifications that significantly change the pI or MW of the protein [6].

\section{Conclusions}

Using a functional proteomics approach we have identified novel changes in mitochondrial protein abundance and PTMs of metabolic proteins in response to I/R. We identified and partially characterized two molecular forms of $\mathrm{PDH}_{\beta E 1}$, which differ due to a novel O-palmitoylation PTM. Also, for the first time we show that I/R induces phosphorylation of $\mathrm{PDH}_{\beta E 1}$, which is associated with a decrease in glucose oxidation during reperfusion. As PDH is the rate-limiting enzyme for glucose oxidation, the regulation of these beta chain modifications may have important implications on the regulation of glucose oxidation in the heart.

\section{Abbreviations}

ATP: adenosine triphosphate; I/R: Ischemia/reperfusion; NADH: Nicotinamide adenine dinucleotide; PDH: pyruvate dehydrogenase; PKA: Protein Kinase A PKC: Protein kinase C; PTM: post-translational modification.

Competing interests

The authors declare that they have no competing interests.

\section{Authors' contributions}

CDLF participated in the study design, performed the isolated rat heart perfusions, performed data and statistical analysis and drafted the manuscript. GS participated in study design, performed the 2-D gel electrophoresis and MS identification of proteins and drafted the manuscript. GM collected the rates of metabolic fluxes in isolated hearts. AJB performed the mitochondrial isolation and revised the manuscript. VJJC performed mitochondria preparation and immunoblot analysis for purity of mitochondria preparation. GDL participated in the study design and drafted the manuscript. All authors have read and approved the manuscript.

\section{Acknowledgements}

CDLF is an Alberta Heritage Foundation for Medical Research (AHFMR) and Canadian Institutes of Health Research (CIHR) doctoral student and a trainee of TomorrOw's Research Cardiovascular Health Professionals (TORCH). GS is a Heart and Stroke Foundation of Canada New Investigator. GDL is an AHFMR Medical Scientist. This work was supported by CIHR grant.

\section{Author Details}

${ }^{1}$ Cardiovascular Research Group and the Departments of Pharmacology and Pediatrics, The University of Alberta, Edmonton, Alberta, Canada, 2Department of Pharmacology, University of Saskatchewan, Saskatoon, Saskatchewan, Canada and ${ }^{3}$ Department of Clinical Chemistry, Medical University of Wroclaw, Wroclaw, Poland

Received: 25 January 2010 Accepted: 9 July 2010

Published: 9 July 2010

\section{References}

1. Fu Q, Van Eyk JE: Proteomics and heart disease: identifying biomarkers of clinical utility. Expert Rev Proteomics 2006, 3:237-249.

2. Yuan C, Ravi R, Murphy AM: Discovery of disease-induced posttranslational modifications in cardiac contractile proteins. Curr Opin Mol Ther 2005, 7:234-239.

3. Schwertz H, Langin T, Platsch H, Richert J, Bomm S, Schmidt M, Hillen H, Blaschke G, Meyer J, Darius H, Buerke M: Two-dimensional analysis of myocardial protein expression following myocardial ischemia and reperfusion in rabbits. Proteomics 2002, 2:988-995

4. White MY, Cordwell SJ, McCarron HC, Prasan AM, Craft G, Hambly BD, Jeremy RW: Proteomics of ischemia/reperfusion injury in rabbit myocardium reveals alterations to proteins of essential functional systems. Proteomics 2005, 5:1395-1410.

5. White MY, Tchen AS, MCCarron HC, Hambly BD, Jeremy RW, Cordwell SJ: Proteomics of ischemia and reperfusion injuries in rabbit myocardium with and without intervention by an oxygen-free radical scavenger. Proteomics 2006, 6:6221-6233.

6. Arrell DK, Elliott ST, Kane LA, Guo Y, Ko YH, Pedersen PL, Robinson J, Murata M, Murphy AM, Marban E, Van Eyk JE: Proteomic analysis of pharmacological preconditioning: novel protein targets converge to mitochondrial metabolism pathways. Circ Res 2006, 99:706-714.

7. Kim N, Lee Y, Kim H, Joo H, Youm JB, Park WS, Warda M, Cuong DV, Han J: Potential biomarkers for ischemic heart damage identified in mitochondrial proteins by comparative proteomics. Proteomics 2006 6:1237-1249. 
8. Zhang J, Liem DA, Mueller M, Wang Y, Zong C, Deng N, Vondriska TM, Korge P, Drews O, Maclellan WR, et al: Altered proteome biology of cardiac mitochondria under stress conditions. J Proteome Res 2008, 7:2204-2214.

9. Stanley WC, Recchia FA, Lopaschuk GD: Myocardial substrate metabolism in the normal and failing heart. Physiol Rev 2005, 85:1093-1129.

10. Liedtke AJ, Demaison L, Eggleston AM, Cohen LM, Nellis SH: Changes in substrate metabolism and effects of excess fatty acids in reperfused myocardium. Circ Res 1988, 62:535-542.

11. Lopaschuk GD, Spafford MA, Davies NJ, Wall SR: Glucose and palmitate oxidation in isolated working rat hearts reperfused after a period of transient global ischemia. Circ Res 1990, 66:546-553.

12. Lerch R, Tamm C, Papageorgiou I, Benzi RH: Myocardial fatty acid oxidation during ischemia and reperfusion. Mol Cell Biochem 1992, 116:103-109

13. Lopaschuk GD, Collins-Nakai R, Olley PM, Montague TJ, Mcneil G, Gayle M, Penkoske P, Finegan BA: Plasma fatty acid levels in infants and adults after myocardial ischemia. Am Heart $J 1994,128: 61-67$.

14. Kantor PF, Dyck JR, Lopaschuk GD: Fatty acid oxidation in the reperfused ischemic heart. Am J Med Sci 1999, 318:3-14

15. Opie LH: Myocardial ischemia--metabolic pathways and implications of increased glycolysis. Cardiovasc Drugs Ther 1990, 4(Suppl 4):777-790.

16. Dennis SC, Gevers W, Opie LH: Protons in ischemia: where do they come from; where do they go to? J Mol Cell Cardiol 1991, 23:1077-1086.

17. Hochachka PW, Mommsen TP: Protons and anaerobiosis. Science 1983, 219:1391-1397.

18. Karmazyn M, Moffat MP: $\mathrm{Na}+/ \mathrm{H}+$ exchange and regulation of intracellular Ca2+. 1993, 27:2079-2080

19. Orchard CH, Houser SR, Kort AA, Bahinski A, Capogrossi MC, Lakatta EG: Acidosis facilitates spontaneous sarcoplasmic reticulum Ca2+ release in rat myocardium. J Gen Physiol 1987, 90:145-165.

20. Carmeliet $\mathrm{E}$ : Cardiac ionic currents and acute ischemia: from channels to arrhythmias. Physiol Rev 1999, 79:917-1017.

21. Liu B, Clanachan AS, Schulz R, Lopaschuk GD: Cardiac efficiency is improved after ischemia by altering both the source and fate of protons. Circ Res 1996, 79:940-948.

22. Taylor SW, Fahy E, Zhang B, Glenn GM, Warnock DE, Wiley S, Murphy AN, Gaucher SP, Capaldi RA, Gibson BW, Ghosh SS: Characterization of the human heart mitochondrial proteome. Nat Biotechnol 2003, 21:281-286

23. Barr RL, Lopaschuk GD: Methodology for measuring in vitro/ex vivo cardiac energy metabolism. J Pharmacol Toxicol Methods 2000, 43:141-152.

24. Idell-Wenger JA, Grotyohann LW, Neely JR: An improved method for isolation of mitochondria in high yields from normal ischemic, and autolyzed rat hearts. Anal Biochem 1982, 125:269-276.

25. Sawicki G, Dakour J, Morrish DW: Functional proteomics of neurokinin B in the placenta indicates a novel role in regulating cytotrophoblast antioxidant defences. Proteomics 2003, 3:2044-2051.

26. Sawicki G, Jugdutt Bl: Detection of regional changes in protein levels in the in vivo canine model of acute heart failure following ischemiareperfusion injury: functional proteomics studies. Proteomics 2004, 4:2195-2202.

27. Zhang X, Shi L, Shu S, Wang Y, Zhao K, Xu N, Liu S, Roepstorff P: An improved method of sample preparation on AnchorChip targets for MALDI-MS and MS/MS and its application in the liver proteome project. Proteomics 2007, 7:2340-2349

28. Pappin DJ, Hojrup P, Bleasby AJ: Rapid identification of proteins by peptide-mass fingerprinting. Curr Biol 1993, 3:327-332.

29. Bizzozero OA: Chemical analysis of acylation sites and species. In Lipid modifications of proteins (Methods in enzymology Volume 250) Volume 250 Edited by: Casey PJ, Buss JE. Academic Press; 1995:361-379.

30. Quin J, Zhang X: Identification of in vivo protein phosphorylation sites with mass spectrometry. In Posttranslational modifications of proteins Tools for functional proteomics Edited by: Kannicht C. Totowa New Jersey Humana Press; 2002:211.

31. Nelson DC, Cox MM: Lehninger Principles of Biochemistry. 3rd edition. New York: Worth Publishers; 2000.

32. Sugden MC, Holness MJ: Mechanisms underlying regulation of the expression and activities of the mammalian pyruvate dehydrogenase kinases. Arch Physiol Biochem 2006, 112:139-149.
33. Kobayashi K, Neely JR: Effects of ischemia and reperfusion on pyruvate dehydrogenase activity in isolated rat hearts. J MolCell Cardio/ 1983, 15:359-367.

34. Churchill EN, Murriel CL, Chen CH, Mochly-Rosen D, Szweda Ll: Reperfusion-induced translocation of deltaPKC to cardiac mitochondria prevents pyruvate dehydrogenase reactivation. Circ Res 2005, 97:78-85.

35. Mayr M, Chung YL, Mayr U, McGregor E, Troy H, Baier G, Leitges M, Dunn MJ, Griffiths JR, Xu Q: Loss of PKC-delta alters cardiac metabolism. Am J Physiol Heart Circ Physiol 2004, 287:H937-945.

36. Mayr M, Liem D, Zhang J, Li X, Avliyakulov NK, Yang Jl, Young G, Vondriska TM, Ladroue C, Madhu B, et al:: Proteomic and metabolomic analysis of cardioprotection: Interplay between protein kinase $C$ epsilon and delta in regulating glucose metabolism of murine hearts. J Mol Cell Cardiol 2009, 46:268-277.

37. Mayr M, Metzler B, Chung YL, McGregor E, Mayr U, Troy H, Hu Y, Leitges M, Pachinger $\mathrm{O}$, Griffiths JR, et al:: Ischemic preconditioning exaggerates cardiac damage in PKC-delta null mice. Am J Physiol Heart Circ Physiol 2004, 287:H946-956

38. Collins-Nakai RL, Noseworthy D, Lopaschuk GD: Epinephrine increases ATP production in hearts by preferentially increasing glucose metabolism. Am J Physiol 1994, 267:1862-1871.

39. Depre C, Ponchaut S, Deprez J, Maisin L, Hue L: Cyclic AMP Suppresses the Inhibition of Glycolysis by Alternative Oxidizable Substrates in the Heart. Journal of Clinical Investigation 1998, 101:390-397.

40. Folmes CD, Clanachan AS, Lopaschuk GD: Fatty acids attenuate insulin regulation of 5'-AMP-activated protein kinase and insulin cardioprotection after ischemia. Circ Res 2006, 99:61-68.

41. Roche TE, Hiromasa Y: Pyruvate dehydrogenase kinase regulatory mechanisms and inhibition in treating diabetes heart ischemia and cancer. Cell Mol Life Sci 2007, 64:830-849.

42. Lee FN, Zhang L, Zheng D, Choi WS, Youn JH: Insulin suppresses PDK-4 expression in skeletal muscle independently of plasma FFA. Am J Physiol Endocrinol Metab 2004, 287:E69-74.

43. Branton WD, Rudnick MS, Zhou Y, Eccleston ED, Fields GB, Bowers LD: Fatty acylated toxin structure. Nature 1993, 365:496-497.

44. Kojima M, Hosoda H, Date Y, Nakazato M, Matsuo H, Kangawa K: Ghrelin is a growth-hormone-releasing acylated peptide from stomach. Nature 1999, 402:656-660.

45. Smotrys JE, Linder ME: Palmitoylation of intracellular signaling proteins: regulation and function. Annu Rev Biochem 2004, 73:559-587.

46. Nestorescu ML, Siess EA, Wieland OH: Ultrastructural localization of pyruvate dehydrogenase in rat heart muscle. Histochemie 1973, 34:355-360.

47. White MY, Edwards AVG, Cordwell SJ, Eyk JEV: Mitochondria: A mirror into cellular dysfunction in heart disease. Proteomics - Clinical Applications 2008, 2:845-861

48. Di Lisa F, Menabo R, Canton M, Barile M, Bernardi P: Opening of the mitochondrial permeability transition pore causes depletion of mitochondrial and cytosolic NAD+ and is a causative event in the death of myocytes in postischemic reperfusion of the heart. J Biol Chem 2001, 276:2571-2575.

49. Fert-Bober J, Basran RS, Sawicka J, Sawicki G: Effect of duration of ischemia on myocardial proteome in ischemia/reperfusion injury. Proteomics 2008, 8:2543-2555.

50. Williams EH, Kao RL, Morgan HE: Protein degradation and synthesis during recovery from myocardial ischemia. Am J Physiol 1981, 240:E268-273

51. Xu Y, Kumar D, Dyck JR, Ford WR, Clanachan AS, Lopaschuk GD, Jugdutt BI: $\mathrm{AT}(1)$ and $\mathrm{AT}(2)$ receptor expression and blockade after acute ischemia-reperfusion in isolated working rat hearts. Am J Physiol Heart Circ Physiol 2002, 282:H1206-1215.

52. Mitch WE, Medina R, Grieber S, May RC, England BK, Price SR, Bailey JL, Goldberg AL: Metabolic acidosis stimulates muscle protein degradation by activating the adenosine triphosphate-dependent pathway involving ubiquitin and proteasomes. J Clin Invest 1994, 93:2127-2133

doi: $10.1186 / 1477-5956-8-38$

Cite this article as: Folmes et al. Novel O-palmitolylated beta-E1 subunit of pyruvate dehydrogenase is phosphorylated during ischemia/reperfusion injury Proteome Science 2010, 8:38 